\title{
LEFT BRANCH EXTRACTION OUT OF THE DETERMINER PHRASE IN SAUDI NORTHERN REGION DIALECT OF ARABIC: A NEW PERSPECTIVE
}

\author{
Khalaf M.J. AlShammiry \\ King Saud University, Riyadh, Kingdom of Saudi Arabia
}

\begin{abstract}
To my knowledge, Left Branch Extraction (LBE) out of the Determiner Phrase (DP) is not previously attested in Modern Standard Arabic (MSA) or any of the Arabic dialects. In Saudi Northern Region dialect of Arabic (SNRDA), the wh-degree question kam "how many/much" can appear at the left periphery of the clause leaving the noun and other postnominal modifiers in the base position, in both the subject and the object positions. In this paper, I will argue for a new perspective for the syntactic phenomenon LBE in which the extracted element is a full DP, not part of a DP as previous studies assume, that moves leaving the other DP in situ. That is to say, I will argue that there are two DPs in the argument position; one of those two DPs is the numeral and the other is all that comes after the numeral including the overt noun and its postnominal modifiers. It is only the wh-item kam "how many/how much", which moves to the left periphery of the clause. My argument is supported, besides other things, by morpho-syntactic similarities between the numeral and the noun, for example both participating in topic and focus constructions and both use of pro-clitic $h$-and the use of the definite article al- "the" with other pre-nominal modifier like the quantifier kil "all" and baadh "some. This paper is unique in that it provides a new perspective on LBE in a dialect of Arabic which is rarely discussed.
\end{abstract}

\section{KEYWORDS: LEFT BRANCH EXTRACTION, DETERMINER PHRASE, ANCHOR, APPOSITIVE, MODERN STANDARD ARABIC, NUMERAL-NOUN CONSTRUCTIONS}

\section{Introduction}

Since Ross's (1967) observation on Left Branch Condition (henceforth LBC) who states that no Noun Phrase (NP), which is the leftmost constituent of a larger NP, can be reordered out of this NP by a transformation rule, LBE phenomenon has been excessively studied in Slavic languages or Latin by Cinque (1980), Shlonsky (1988), Giorgi and Longobardi (1991), Uriagereka (1988), Corver (1990, 1992, 1997, 2006), van Kampen (1994, 1997, 2000), Boskovic (2005, 2008), Ntelitheos (2002), Kayne (2002), Gavarro and Sola (2004), Gavruseva (2000), Gavruseva and Thornton (2001), and Kim (2011), among others. To my knowledge, LBE out of the DP is not previously attested in Modern Standard Arabic (MSA) or any of the Arabic dialects. In SNRDA, the wh-degree question kam "how many/much" can appear at the left periphery of the clause leaving the noun and other postnominal modifiers in the base position, in both the subject and the object positions. In this paper, I will argue for a new perspective for the syntactic phenomenon LBE in which a full DP moves, not part of a DP as previous studies assume, leaving the other DP in situ. That is to say, I will argue that there are two DPs in the argument position; one of those two DPs is the numeral and the other is all that comes after the numeral including the overt noun and its postnominal modifiers. It is only the wh-item kam "how many/how much", which moves to the left periphery of the clause. Following Vries (2006), I will take 
the numeral to be the anchor and all that follows it is the appositive. Using Chomsky's (1995) economy condition which states ' $F$ ' carries along just enough material for convergence, in Kam-wh-questions, it is only the wh-item kam "how many/how much", the anchor, which moves to the left periphery of the clause. My argument is supported, besides other things, by morpho-syntactic similarities between the numeral and the noun, for example both participating in topic and focus constructions and both use of pro-clitic $h$ - and the use of the definite article al- "the" with other pre-nominal modifier like the quantifier kil "all" and baadh "some. This paper is unique in that it provides a new perspective on the $\mathrm{LBE}$ in a dialect of Arabic which is rarely discussed.

The paper is structured as follows. In section 2, I present data under investigation. Section 3 reviews some of the literature on LBE. In section 4, the internal structure and the different syntactic analyses of the DPs in MSA proposed are discussed. Numerals "cardinals" are discussed in section 5. Section 6 discusses the internal structure of DPs in SNRDA. Section 7 provides pieces of evidence of the full DP nature of the numeral in SNRDA. Section 8 concludes the paper.

\section{Data under investigation}

To structure a degree question with kam "how many/much" speakers of SNRDA may shift only the wh-element kam "how many/much" to the left periphery of the clause leaving behind the nominal with its post nominal modifiers.

1. a. sharait thalaath sayyaraat beedh bought.I three cars white.pl.fem.

"I bought three white cars."

b. $\mathrm{kam}_{\mathrm{i}} \quad$ sharait $\mathrm{t}_{\mathrm{i}}$ sayyaarah beedha?

how many bought a car white.sing.fem.

"How many white cars did you buy?"

2. a. sharait thalaath kiliwaat sikar bought.I three kilos sugar

"I bought three kilos of sugar."

b. kam $_{\mathrm{i}} \quad$ sharait $\mathrm{t}_{\mathrm{i}}$ kilo sikar?

how many bought kilo sugar

"How many kilos of sugar did you buy?"

"How much sugar did you buy?"

We could see that in ( $1 \mathrm{~b}$ and $2 \mathrm{~b}$ ), kam "how many" is spelled out at the left periphery of the clause leaving sayyarah beedha "a white car" and kilo sikar "kilos of sugar" stranded behind.

As another option, speakers may also move kam "how many/much" and all that follows it including the noun to the left periphery of the clause.

3. kam sayyaarah $h_{i}$ beedha sharait $t_{i}$ ?

how many a car white bought

"How many white cars did you buy?"

4. kam kilo sikari sharait $t_{i}$ ?

how many kilo sugar bought

"How many kilos of sugar have you bought?"

"How much sugar did you buy?" 
We could see that in (4 and 5), kam sayyarah "how many cars" and kam kilo sikar "how much sugar" are spelled out at the left periphery of the clause.

kam-wh-questions cases in all the aforementioned examples are formed out of the object position. kamwh-questions can also be formed out of the subject position.

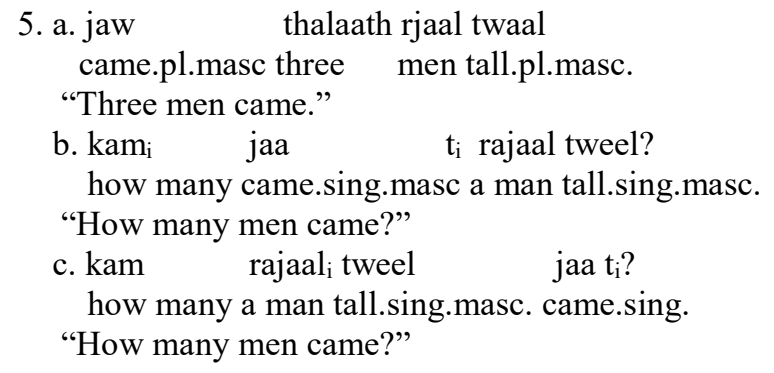

We could see from (5b) that kam "how many" is moved from the object position to the left periphery of the clause; and in $(5 \mathrm{c}), \mathrm{kam}$ and the noun following it including the modifier are moved to the left periphery of the clause.

kam-wh-questons are also formed out of verbless sentences.

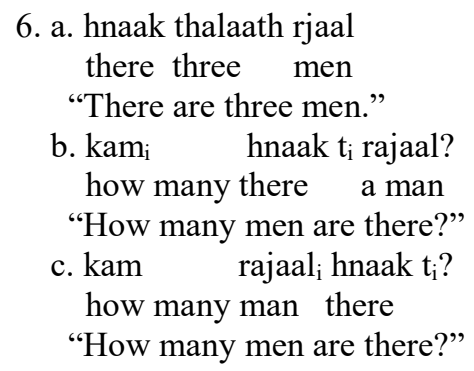

We could see from (6b) that kam "how many" is moved to the left periphery of the clause stranding the noun following it rajaal "man" in the base position; and in (6c) kam, is moved with the noun following it to the left periphery of the clause.

This stranding option is not found with quality degree questions as there is no Arabic equivalent for the English construction "how adjective". Speakers use constructions like "kam noun" and "wish noun"

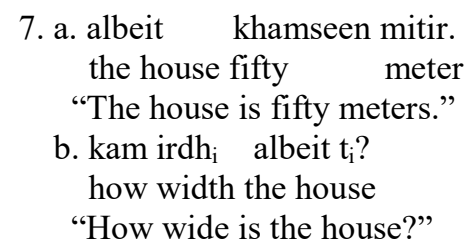

We could see that in (7b), the quality degree question is formed with the use of the word kam "how" followed by the noun irdh "width".

As a matter of fact, questions formed out of the word kam "how many/much" can take place across clause boundaries. 


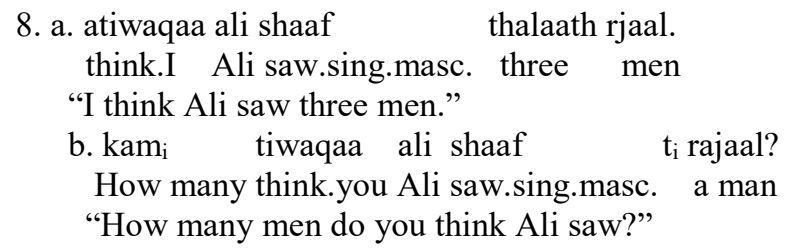

In (8b), we could notice that kam "how many" crosses two clauses; one clause is the embedded clause which starts with the verb shaaf "saw" and the other clause is the matrix one which starts with the verb tiwaqaa "think". I will just argue that there are two full DPs in the argument position, not only one, the first of which is the numeral which moves to the left periphery of the clause leaving the other DP the noun and its modifiers in-situ. Next, I review the literature on left branch extraction(LBE).

\section{Left Branch Extraction (LBE)}

LBE phenomenon has been extensively discussed before and after minimalist program by Ross (1967), Obenauer (1984), Uriagereka (1988), Gavruseva and Thornton (2001), Hoekstra, Jan and Thomas (1992), Franks and Progovac (1994), van Kampen (1994, 1997, 2000), Corver (1990, 1992, 1997, 2006), Kayne (2002), Boskovic (2005), and Kim (2011), among others. Before minimalist program, in languages which ban LBE, this phenomenon is attributed to a locality principle, Empty Category Principle (ECP), Chomsky (1981) and Corver (1990, 1992, 1997, 2006). In this account, the trace left behind is not properly governed; and even the existence of other governors outside the Noun Phrase (NP), Verb Phrase (VP) and Inflectional Phrase (IP), does not save the construction as they do not have access to the spec of NP.

In languages that allow fronting of the Adjective Phrase (AP), following Abney's (1987) AP analysis in which the AP is followed by the NP as a complement, Franks and Progovac (1994), propose that LBE of the adjective involves remnant movement of the adjective; in this analysis, first, the NP moves out of the AP, followed by fronting of the AP to a position at the left periphery of the clause adjoining it to the IP.

Adopting Emond's (2000) Noun-Case proposal, Kayne (2002) dealing with English and French data also proposes a remnant movement analysis of the NP. Kayne assumes that LBE phenomenon takes place with split case licensing; putting it differently, Kayne assumes that the NP inside the Quantifier Phrase (QP) in English sentences for example is case licensed independently by a functional category (K-of/de) to which the NP moves. (For more details on remnant analysis of the DP, see Kaynes's (2002))

The most recent work accounting for LBE that has come out is Boskovic's $(2005,2008)$ DP/NP parameter. Following Abney's (1987) and Uriagereka's (1988) DP/NP language proposal, Boskovic proposes that there are two types of languages in terms of whether the language allows or does not allow LBE of the Adjectives, DP and NP languages; and that a DP is a phase and the spec of the DP is an escape hatch for phrasal movement outside the DP. In DP languages, like English and Macedonian, in which the A takes NP as its complement, the DP blocks AP left-branch extraction, since this movement violates anti-locality; whereas in NP languages, like Polish and Czech, which do not have DP and in which the noun (N) takes AP as its spec, left-branch extraction is allowed.

9. a. He respects the smart student.

b. ${ }^{*}$ smart $_{i}$, he respects [the $t_{i}$ students] 


\section{0. a. Skupa $/$ ta je video $\left[\mathrm{t}_{\mathrm{i}}\right.$ car]} Expensive/that is seen car

We could see from the English example in (9) that extraction of the English adjective smart is not allowed, whereas, in the Serbo-Croatian example in (10), the adjective skupa "expensive" is extracted.

The above analysis accounts for the ban of adjunct extraction in English; but not in NP languages.

11. a. Peter read [DP books from that shelf]

b. *From which shelf $f_{i}$ did Peter read book $t_{i}$ "

In NP languages, adjunct extraction is allowed.

12. [iz kojeg grada $]_{i}$ je Ivan sreo [djevojde $t_{i}$ ]

From what town is Ivan met girls

"Ivan met girls from which town?"

From all the above LBE proposals, one could conclude that LBE takes place when part of the DP, the noun or the adjective, is moved to the left periphery of the clause. And before proceeding, I would like to emphasis that I am not defending or falsifying any of the above analyses in this paper, I will just argue for a new perspective for this syntactic phenomenon, LBE, in which the LBE takes place out of two full DPs in the argument position, not only one part of which moves, the first of which is the numeral which moves leaving the other DP the noun and its modifiers in-situ. Next, I discuss the internal structure and the syntactic analyses proposed for DPs in MSA.

\section{The Internal Structure and the Different Syntactic Analyses of the DPs in MSA}

\section{The internal structure of the DPs in MSA}

The internal structure of DPs in Modern Standard Arabic has been investigated excessively, (See Fassi (1989, 1993, 1997, 1998, 1999), Mohammad (1988, 1999), Ritter (1987, 1988, 1991), Benmamoun (2000), Siloni (1991ab, 1994, 1997, 2002), Shlonsky (1988, 1991, 2002, 2004, 2012) and Kremers (2003)). There is a consensus that there are two types of DPs in Arabic: simple and complex DPs. The simple DP is formed out of either a definite article al- "the" or an indefinite marker $-n$, and a noun which could be followed by a modifier or more. The complex DP is formed out of a head noun and genitive DP complement which could be followed by a modifier or more. Adjectives always fully agree with nouns they modify in definiteness, gender and case.

$$
\begin{aligned}
& \text { 13. a. al-rajul-u } \\
& \text { the-man-nom } \\
& \text { "the man" } \\
& \text { b. al-rajul-u al-tayyib-u } \\
& \text { the-man-nom the-decent-nom } \\
& \text { "The decent man" } \\
& \text { 14.a. bait-u al-rajul-i } \\
& \text { house-nom the-man.gen } \\
& \text { "The man's house" } \\
& \text { b. bait-u al-rajul-i al-wasia } \\
& \text { house-nom the-man-gen the-wide } \\
& \text { "The man's wide house" }
\end{aligned}
$$


In (13b), in the simple DP, we could see that the modifier al-tayyibi "the decent" follows the noun alrajulu "the man" and adjacent to it. In (14b), in the complex DP, the modifier al-wasia "the wide" follows the construct state baitu al-rajuli "the man's house.

Demonstrative pronouns and cardinals appear prenominally in simple DPs. In this case, the demonstrative pronoun is always without an overt case marker; whereas cardinal is marked with a case depending on the position it occupies.

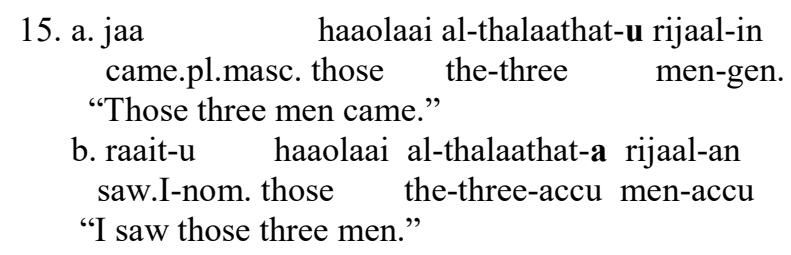

In (15a), the cardinal al-thalaathat- $\boldsymbol{u}$ "the three" in the subject carries a nominative case marker $-\boldsymbol{u}$, while it carries an accusative case maker $-\boldsymbol{a}$ in the object position in (15b). Moreover, nouns following cardinals get different cases depending on the cardinal used.

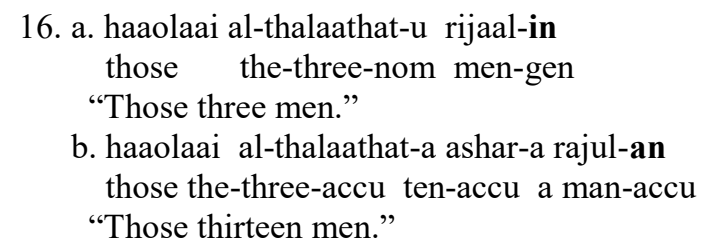

We could see that in (16a), the noun rijaal-in "men" following the cardinal al-thalaathat-u "the three" carries the genitive case marker - in, while it carries an accusative case maker -an after the cardinal althalaathat-a ashar-a "thirteen" in (16b).

In complex DPs, demonstrative pronouns and cardinals follow the noun.
17. kitaab-u al-taalib-i haatha book-nom the-student-gen this.masc.
"This student's book"
18. kutub-u al-taalib-i al-thalaathat-u books-nom the-student-gen the-three-nom
"The student's three books"

In (17 and 18), we could see that the demonstrative pronoun haatha "this" and the cardinal althalaathat- $u$ "the three" appear after the construct estate.

In postnominal positions, cardinals always agree with noun they modify in case and other phi features.

$$
\begin{aligned}
& \text { 19. al-asilat-u al-thaalathat-u } \\
& \text { the-questions-nom. the-three-nom } \\
& \text { "The three questions." }
\end{aligned}
$$

In (19), the noun alasilat- $u$ "the questions" is definite and is assigned nominative case and the cardinal number following the noun al-thalaathat- $u$ "the three" is also definite and assigned nominative case. 
(see Fassi fehri's (1999) paper in which Fassi argues that postnominal modifiers appear in a fixed word order in Modern Standard Arabic.)

Quantifiers in MSA also appear prenominally before the demonstrative pronouns; those quantifiers cannot take the definite article.

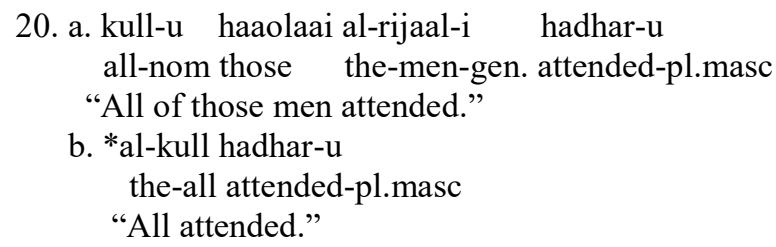

We could see in (20a), the quantifier $k u l$ "all" appears to the left of the demonstrative pronoun haaolaai "those"; and in (20b), the use of the definite article al- "the" renders the statement ungrammatical. After providing a detailed explanation of the internal structure of the DPs in MSA, in the next subsection, I discuss the different syntactic analyses of the DPs in MSA.

\section{Syntactic Analyses of DPs in MSA}

Generally, following Abney (1987) who proposes a parallel structure to both the clause and the noun phrase, most studies done on DPs in Arabic assume that the noun starts below in the structure and moves up ending in a position preceding all adjectives (See the work of Fassi (1989, 1993, 1997, 1998, 1999), Mohammad (1988, 1999), Ritter (1987, 1988, 1991) and Benmamoun (2000)). There are linguists who advocate head noun movement approach in which the head noun is base generated as a head of an NP and for case requirements among other things it raises cross its modifiers adjoining to D. Others advocate the noun raising to the spec of DP as the head noun movement violates some syntactic operations like Empty Category Principle (ECP) and Extended Projection Principle (EPP). In simple DPs, taking definiteness/indefiniteness in Arabic as affixal in nature, after the noun moves, it merges with the definite/indefinite article after spell out(A Phonological Form (PF) process).

Shlonsky's (2012) proposes what he refers to snowball movement. According to his proposal, there is an Agr head inside the DP which c-commands all functional heads DP like Adjective Phrase (AP), Cardinal Phrase (CardP), etc, and the NP moves upward piped piping all the material it c-commands. Shlonsky assumes that the determiner, the definite article, in AP is a head in its own projecting a DP rather than a feature. Shlonsky, contrary to Abney's, assumes that there is a noun phrase movement rather than a head movement. To put it differently, to him, the internal structure of the DP differs from complementizer Phrase (CP).

After reviewing briefly on the analyses of the Arabic DPs, we could say that all analyses share one thing, which is that the prenominal cardinal and the noun as well as the modifiers that follow the noun are all elements that are sandwiched between the DP and the NP. In other words, it is one DP within which various movement processes take place. Again, the assumption which I will defend in this paper is that in this dialect in the argument position there are two DPs, rather than one DP; one DP is the cardinal and the other DP is the noun that follows the cardinal including the modifiers that follow it. Following Vries (2006), I will take the first DP, the cardinal, to be the anchor and the second DP, the noun and its postnominal modifiers, the appositive. As a matter of fact, speakers of SNRDA use the noun with/out postnominal modifiers after the cardinal to add more information about the first DP, the cardinal. Before discussing DPs in SNRDA and providing evidence for my main argument, in the next section, I discuss numerals "cardinals" in MSA and their relations to nouns following them in numeralnoun constructions. 


\section{Numerals "Cardinals" in MSA}

The syntax of cardinals in numeral-noun constructions has been the focus of many studies. (see Corbett (1978), baker (2003), Ritter (1991), Nelson and Toivonen (2000), Ionin and Matushansky (2006), Danon (1996, 1998, 2012), Borer (2005), Shlonsky (2004), Corver and Zwarts (2004), Zabbal (2005), Zweig (2005), and Ouwayda (2010, 2012, 2013, 2014.), among others). Researchers in those studies are divided into groups; those who view most of the cardinals as nouns, Hurford (1975, 1987, 2001, 2003) and Covert and Zwarts (2004) and those who view cardinals as adjectives, Stavrou and Terzi (2008). Other researchers view high numerals as adjectives and low ones as nouns (Zabbal 2005). Others like Corbett (1978) and Baker (2003) view higher numerals as nouns and lower ones as adjectives. In Zweig's (2005) work, Zweig shows that numerals vary across languages. From all those views, we can say that numerals are sometimes treated as heads that select a projection of the noun and sometimes as phrases located in the specifier of a functional projection of the noun ; Danon (2012) argues that both structures are available at Universal Grammar (UG) in some languages like Hebrew. Hurford (2003) doing a survey shows cardinal numerals can be combined in a number of ways with nouns; and categories like gender, number, case, and definiteness are marked differentially on numerals and nouns. Moreover, morphologically speaking, the nature of the interaction between the numeral and the noun following it is not always the same. That is to say, the interaction process sometimes operates in both directions; from noun to numerals or from numerals to nouns; and sometimes the process is not clear.

As for numerals and their relation to nouns in numeral-noun constructions in Arabic, the interaction seems to be supporting Hurford's (2003) conclusion; there are actually a number of ways in which cardinal numbers interact with the nouns following them. Following is a table that summarizes some of the numerals in MSA and their counterparts used in SNRDA and their relation to the nouns following them.

Table 1: Some of the Numerals and their Relation to Nouns in MSA and SNRDA

\begin{tabular}{|l|l|l|}
\hline The Numeral & \multicolumn{1}{|c|}{ MSA } & \multicolumn{1}{|c|}{ SNRDA } \\
\hline $1-2$ & $\begin{array}{l}\text { agrees in gender with the noun } \\
\text { rajulun waahidun } \\
\text { a man.nom. one.masc.nom. } \\
\text { imraatun waahidatun } \\
\text { a woman.nom one.fem.nom. }\end{array}$ & $\begin{array}{l}\text { agrees in gender with the noun } \\
\text { rajaal waahid } \\
\text { a man one.masc. } \\
\text { marah wihdah } \\
\text { woman one.fem. }\end{array}$ \\
\hline $3-10$ & $\begin{array}{l}\text { plural, opposite gender of the noun } \\
\text { thalaathatu rijaalin } \\
\text { three.fem.nom. men.gen. } \\
\text { "three men" } \\
\text { thalaathu niswahin } \\
\text { three.masc.nom women.gen. } \\
\text { "three women" }\end{array}$ & $\begin{array}{l}\text { sexes takes the same gender form with both } \\
\text { thalaath rjaal/hareem } \\
\text { three men/women } \\
\text { "three men/woman" }\end{array}$ \\
\hline $11-19$ & $\begin{array}{l}\text { singular, 10 always agrees with the noun } \\
\text { while 3-9 always disagree with it } \\
\text { thalaathata ashara rajulan } \\
\text { three.fem.accu ten.masc.accu. a man.acc. } \\
\text { "thirteen men" } \\
\text { thalaatha ashrata imraatan } \\
\text { three.masc.accu. ten.fem.accu woman.acc. } \\
\text { "thirteen women" }\end{array}$ & $\begin{array}{l}\text { always takes the same gender form with both } \\
\text { sexes } \\
\text { thalathTaash rajaal/marah } \\
\text { thirteen men/woman } \\
\text { "thirteen men/woman" } \\
\text { twotice here that thirteen is one word while its } \\
\text { two } \\
\text { numbers (11-19). }\end{array}$ \\
\hline
\end{tabular}




\begin{tabular}{|l|l|l|}
\hline 20-90 & singular, always invariable; changes & always takes the same gender form with \\
with case only. & both sexes \\
& ishruuna rajulan/imraatan \\
twenty.nom. man/woman.accus. & ishreena rajaal/marah \\
& twenty men/woman" \\
& $\begin{array}{l}\text { ishreena rajulan/imraatan } \\
\text { twenty.accus./gen. man/woman.accus. } \\
\text { "twenty men/woman" }\end{array}$ & \\
& \\
\hline
\end{tabular}

As the table shows, morpho-syntactically, the numeral system in MSA is very complicated. Nouns following numerals 3-10 are always plural; and they disagree with the noun and receive genitive case whereas nouns following numerals 11-19 are always singular and receive accusative case; and the numeral 10 agrees with the noun while the numerals 3-9 disagree with it. As far as numerals in the dialect under investigation is concern, we could notice that they always take the same gender form with both sexes.

As I have shown earlier, in MSA, numerals appear in prenominal and postnominal position. In prenominal position, they influence the noun following them by determining its morphological case. In postnominal position, their behavior is very similar to those of the adjectives. For that, Shlonsky (2004) argues that numerals are like adjectives; prenominally, they are heads taking the noun as a complement; postnominally, they are phrases in the specifier position. After reviewing the literature on numerals and their relation to the noun following them in numeral-noun constructions in MSA, in the following two sections, I discuss the structure of the DPs in SNRDA and provide pieces of evidence of my main argument in this paper.

\section{The Internal Structure of the DPs in SNRDA}

As in MSA, DPs in the dialect under investigation are either simple or complex. Demonstrative pronouns and the cardinals precede the noun in simple DPs. In complex DPs, only demonstrative pronouns follow the noun. As for cardinals, unlike DPs in MSA, they precede or follow the noun in complex DPs.

21. hathuula althalaath alrjaal altwaal

Those.masc the.three the.men the.tall.pl.masc

"Those three tall men"

22. a. bait alrijil aljamil hatha house the.man the.beautiful.masc this.masc

"This man's beautiful house"

b. *hatha bait alrijil aljamil this.masc house the.man the.beautiful.masc

"This man's beautiful house"

23. a. thalaath sayyarat ali three cars Ali

"Ali's three cars."

b. sayyarat ali al-thalaath cars Ali the-three

"Ali's three cars." simple DP

complex DP

complex DP

complex DP

complex DP 
In (21), like in simple DPs in MSA, we could see that the demonstrative pronoun hathuula "those" and the cardinal althalaath "the three" precede the noun alrijaal "the men" and the adjective altwaal "the tall" follows it. Again, like in complex DPs in MSA, the demonstrative pronoun hatha "this" follow the noun in (22). However, unlike MSA, the cardinal thalaath "three" can precede and follow the construct estate sayyarat ali "Ali's cars" in (23).

Unlike MSA, as in other dialects of Arabic, words are not marked with case; and postnominal adjectives do not follow a particular order.

24. a. hathuula althalaath alrjaal altwaal alhabeebeen those.masc the.three the.men the.tall.pl.masc the.decent.pl.masc

b. hathuula althalaath alrjaal alhabeebeen altwaal those.masc the.three the.men the.decent.pl.masc the tall.pl.masc "Those three tall men"

In (24ab), we could see that the words are not marked with case and the two postnominal adjectives alhabeebeen "the decent" and altwaal "the tall" can freely exchange their positions. After discussing the internal structure of DPs in SNRDA, in the next section, I provide pieces of evidence to support my main argument that the numeral prenominally in SNRDA is actually a full DP, and the noun following it with its modifier is another DP.

\section{Evidence of the Full DP nature of the Numeral in SNRDA}

\section{The morpho-Syntactic Similarity Between Numerals and Nouns}

The first piece of evidence supporting my main argument is the syntactic similarity between numerals and nouns. First, as other nouns, numerals host the definite article $a l$ - "the".

\section{5. al-khams \\ "the five"}

Second, numerals can be pluralized; in other words, plural suffix can be attached to them.

$$
\begin{aligned}
& \text { 26. khamsaat } \\
& \text { five.pl.fem. } \\
& \text { "Fives" }
\end{aligned}
$$

Third, they can also be modified by VP, PP and AP.

27. shift thalaath waqfeen

saw.I three standing.pl.masc

"I saw three standing."

28. shift thalaath bikhwath saw.I three in.helmets

"I saw three with helmets."

29. shift thalaath athkiyaa saw.I three smart.pl.masc

"I saw smart three." 
Forth, numerals can also be conjoined with other nouns.

30. thataath $w$ bint jaw

three and a girl came

"Three and a girl came."

Fifth, numerals can be preceded by a preposition.

\section{1. tazawajt b-thalaath \\ married.I in-three \\ "I married to three."}

Moreover, and as I have stated earlier, numerals in MSA also receive case, nominative, accusative and genitive according to the position they occupy.

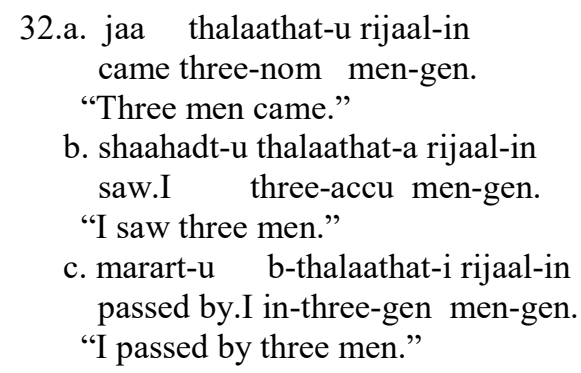

Finally, the numeral is also used as a possessed noun.

33. thalaathat ali jaw

three Ali came

"The three of Ali's/Ali's three came."

From all above morpho-syntactic properties one would conclude that those numerals are in fact full DP phrases. The second piece of evidence supporting my main argument comes from the case marking the noun following the numeral in MSA; this is discussed next.

\section{The Case of the Noun Following Numerals}

My second piece of evidence comes from MSA. Recall that I have shown, in MSA, numerals, not the noun following them, receive case depending on the position they occupy, and that nouns following them may receive accusative or genitive case depending on the numeral.

34.a. jaa thalaathat-u rijaal-in came three-nom men-gen

"Three men came."

b. shahadtu thalaathat-a rijaal-in saw.I three-nom men-gen "I saw three men."

35.a. jaa thalaatuuna rajul-an came thirty.nom men-accus. "Thirty men came."

b. shahadtu thalaathiina rijaal-an 
saw.I thirty.accu men-accus.

"I saw thirty men."

In (34 and 35), we could see that the noun case varies depending on the numeral preceding it. In (34ab), the noun rijaal-in "men" following the numeral thalaathatu/thalaathata "three" receives a genitive case; whereas in (35ab) it receives an accusative case when following the numeral thalaathuun/thalaathiina "thirty". Therefore, one does not want to say that numerals as heads assign different cases. The question is how those cases are assigned? Bearing in mind what Hurford (2003) shows about the complexity of the relationship between the numerals and the nouns following them with regard to case, definiteness and phi feature, one might not want to let the case issue stands as an obstacle of a better argument. Therefore, those linguists like Shlonsky who use the genitive case as a base for their analysis of DPs in Arabic would need to revise their analyses accordingly. Next, the use of the pro-clitic $h$ - with both DPs in SNRDA is another piece of evidence for my main argument.

\section{The Use of the Pro-Clitic h- in SNRDA}

The third piece of evidence of the existence of two DPs is the use of the pro-clitic $h$ - "this/those" in SNRDA, a pro-clitic which is in complementary distribution with the demonstrative pronouns hathaa "this", hathuula "those.masc" and hatheelin "those.fem". This pro-clitic cliticizes onto the left edge of the DP.

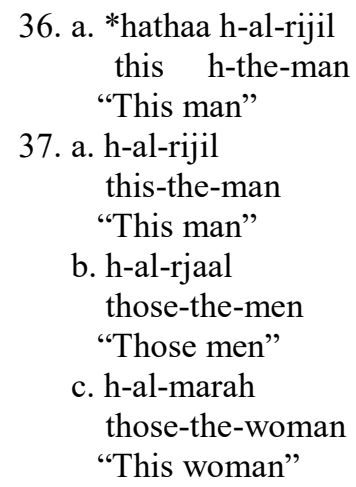

We could see from (36a) that the use of the demonstrative pronoun hathaa "this" and the pro-clitic $h$ "this/those" renders the sentence ungrammatical. In (37abc), we could see that the pro-clitic is attached to singular and plural nouns, feminine and masculine. The same pro-clitic can appear cliticizing onto both the numeral and the DP following it.

$$
\begin{aligned}
& \text { 38. jaw h-al-thalaath h-al-rjaal al-twaal } \\
& \text { came those-the-three those-the.men the-tall.pl.masc } \\
& \text { "Those three men came" }
\end{aligned}
$$

We could see from (38) that the pro-clitic $h$ - "those" cliticizes onto the numeral al-thalaath "the three" and the noun al-rjaal "the men", but not onto the adjective following the noun al-twaal "the tall". This fact supports my main argument that there are two DP phrases the first of which is the numeral. My next piece of evidence for my main argument comes from the topic and focus constructions in SNRDA. 


\section{Topic and foci Constructions in SNRDA}

The forth piece of evidence for my argument of the existence of two DPs is the fact that numerals can appear at the left periphery of the clause as topics and foci stranding the noun and the postnominal modifiers behind.

39. althalaat, shifti-hin albanaat altiweelaat

the.three saw.I-them.fem the.girls the.tall.pl.fem.

"As for the three tall girls, I saw them."

We could see in (39) that the numeral althalaat "the three" appears at the left periphery of the clause interpreted as a topic and the resumptive pronoun hin "them" appears in the base position. Moreover, the numeral can appear at the left periphery of the clause as a focus.

40. THALAATH, shift banaat tiweelaat

THREE (not two) saw.I girls tall.pl.fem.

"THREE tall ones, I saw."

We could see in (40) that the numeral thalaat "three" appears at the left periphery of the clause interpreted as a focus leaving in base position behind the noun and the postnominal modifier banaat tiwelaat "tall girls".

Moreover, both the numeral and the noun with its modifier can appear at the left periphery of the clause for topic and focus purposes.

41. banaat tweelaat, THALAATH, shift girls tall.pl.fem THREE (not two) saw.I

"As for tall girls, THREE, I saw."

In (41), the numeral thalaath "three" appears at the left periphery of the clause interpreted as a focus and the noun and the postnominal modifier banaat tiwelaat "tall girls" as a topic. Moreover, when forming kam-wh-questions, the noun in the numeral-noun constructions can appear in the base position and it can appear at the left periphery of the clause as a topic.

42. a. kam shift banaat tiweelaat how may saw.you girls tall.pl.fem.

"How many tall girls did you see?"

b. banaat tweelaat kam shift

girls tall.pl.fem how many saw.you

"As for tall girls, how many did you see?"

In (42a) the wh-word kam "how many" appears at the left periphery of the clause leaving the noun and its postnominal modifier bannaat tiweelaat "tall girls" in situ. In (42b), we could see that the noun and postnominal modifier bannaat tiweelaat "tall girls" with a topic interpretation appear at the left periphery of the clause to the left of the wh-item kam "how many". The last piece of evidence, contrary to MSA, speakers of this dialect use the definite article al- "the" with other pre-nominal modifier like quantifier kil "all" and baadh "some"; in this case, the quantifier functions as a full DP phrase. 


\section{The Use of the Definite Article al- "the" with Quantifiers}

Contrary to MSA, speakers of this dialect use the definite article al- "the" with other pre-nominal modifier like quantifier kil "all" and baadh "some".

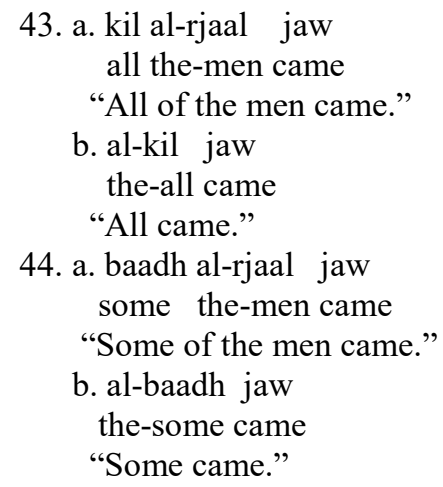

We notice in (43b and 44b) that the definite article al- "the" cliticizes onto the quantifiers kil "all" and baadh "some". Before concluding this paper, it is important to say that some speakers may optionally use the preposition $\mathrm{min}$ "from/of" when forming a degree questions. (Thorne (1993) investigating Welsh shows that there is no difference in meaning between sentences with or without the use of the preposition).

\section{5. kam shift (min) rajaal tweel \\ how many saw out of a man tall.sing.masc \\ "How many tall men did you see?"}

In (45), we could see the optional use of the word min "out of" before the noun rjaal "man"; what is important here is that the interpretation of the structure with or without $\mathrm{min}$ "out of" is the same.

To sum up, in this last section, I have provided pieces of evidence to support my argument of the full DP nature of the numeral and the existence of two DPs in the argument position. My pieces of evidence are mainly the morpho-syntactic similarities between the numeral and the noun, the case of the noun following the numerals, the use of pro-clitic $h$ - with both the numeral and the noun and the fact that the numeral and the noun following it as separate DPs can participate in topic and focus constructions. Moreover, I have shown that other pre-nominal modifier like the quantifier kil "all" and baadh "some" can take the definite and function as full DPs. From these pieces of evidence, I conclude that the numeral is a full DP; all that follows the numeral is another full DP including the noun and its modifiers. Following Vries (2006), I will assume that the numeral is an anchor whereas the noun following it with its modifiers is an appositive. Adopting Chomsky's (1995) economy condition which states " $F$ ' carries along just enough material for convergence, I argue it is only the wh-item kam "how many/how much", the anchor, which needs to move to the left periphery of the clause leaving the noun and its modifiers, the appositive, in situ.

\section{Conclusion}

In this paper, I have accounted for the fact that, in SNRDA, the wh-degree question kam "how many/much" can surface at the left periphery of the clause leaving the noun and other postnominal modifiers in the base position, in both the subject and the object positions. I have argued for a new perspective of the LBE phenomenon in which there are two DPs in the argument position; one of those 
two DPs is the numeral and the other is all that comes after the numeral including the overt noun and the postnominal modifiers; and it is the first DP, the numeral, which moves to the left periphery of the clause leaving the other DP in situ. Following Vries (2006), I took the numeral to be the anchor and all that follows it is the appositive. Using Chomsky's (1995) economy condition which states ' $F$ ' carries along just enough material for convergence, in Kam-wh-questions, it is only the wh-item kam "how many/how much", the anchor, which moves to the left periphery of the clause leaving the noun and its modifier, the appositive, in situ. My argument is supported, besides other things, by morpho-syntactic facts mainly the syntactic similarities between the numeral and the noun, for example both participating in topic and focus constructions and both use of pro-clitic $h$ - and the use of the definite article $a l$ - "the" with other pre-nominal modifier like the quantifier kil "all" and baadh "some. The data and the conclusion the paper reaches add to our understanding of the LBE phenomenon; LBE not only takes place in one DP in which part of that DP moves to the left periphery of the clause it can also take place from two DPs in the same argument position the first of which moves.

\section{References}

Abney, S. (1987). The English Noun Phrase in its Sentential Aspect. PhD Dissertation, MIT, Cambridge, Massachussets.

Baker, M. (2003). Lexical Categories: Verbs, Nouns and Adjectives. Cambridge: Cambridge University Publication.

Benmamoun, E. (2000). The Feature Structure of Functional Categories: A Comparative Study of Arabic Dialects. Oxford: Oxford University Press.

Borer, H. (2005). Structuring Sense, Vol. 1: In Name Only. Oxford University Press, Oxford.

Boskovic, Z. (2005). On the Locality of Left Periphery Branch Extraction and the Structure of NP. Studia Linguistica 59: 1-45.

Boskovic, Z. (2008). What Will You Have, DP or NP? Proceedings of NELS 37.

Chomsky, N. (1981). Lectures on Government and Binding. Dordrecht, Foris.

Chomsky, N. (1995). The Minimalist Program. Cambridge, MA, MIT Press.

Cinque, G. (1980). On Extraction from NP in Italian. Journal of Italian Linguistics 1. 47-99.

Corbett, G. (1978). Universals in the Syntax of Cardinal Numbers. Lingua 46: 355-368.

Corver, N. (1990). The Syntax of Left Branch Extractions. PhD dissertation, University of Tilburg.

Corver, N. (1992). On Deriving Certain Left Branch Extraction Asymmetries: a Case Study I Parametric Syntax. In Proceedings of the North East Linguistic Society 22, ed. K. Broderick, 67-84. Amherst: GLSA, U. of Massachusetts.

Corver, N. (1997). The Internal Syntax of the Dutch Extended Adjectival Projection. Natural Language and Linguistic Theory 15: 289-368. 
Corver, N. (2006). Subextraction. In the Blackwell Companion to Synax, ed. By Martin Everaert and Henk van Riemsdijk, Vol. 1, 566-600. Malden: Blackwell Publishing Ltd.

Corver, N. and Zwarts, J. (2004). Pre-positional Nominals. Lingua 116: 811-835.

Danon, G. (1996). The Syntax of Determiners in Hebrew. Unpublished MA. Tel Aviv University.

Danon, G. (1998). Two Syntactic Positions for Determiners in Hebrew. In Proceedings of Israel Association of Theoretical Linguistics (IATL) 13, 55-73. Adam Zachary Wyner (ed.). RamatGan: Bar-Ilan University.

Danon, G. (2012). Two Structures for Numeral-Noun Constructions. Lingua 122 (12).

Emond, J. (2000). Lexicon and Grammar: The English Syntaction. Berlin: Mouton de Gruyter.

Fassi Fehri, A. (1989). Generalized IP Structure, Case, VS Order. In I. Laka and A. Mahajan (ed.), MIT Working Papers in Linguistics, Cambridge 10: 75-113.

Fassi Fehri, A. (1993). Issues in the Structure of Arabic Clauses and Words. Dordrecht: Kluwer.

Fassi Fehri, A. (1997). Arabic Antisymmetrical Adjectives and Possessive Structure. Linguistic Research 4.

Fassi Fehri, A. (1998). Layers in the Distribution of Arabic Adverbs and Adjectives and their Licensing. Perspectives on Arabic Linguistics 11, (ed.) by Benmamoun Elabbas, Mushira Eid and Niloofar Haeri, 1-45. Philadelphia: John Benjamins.

Fassi Fehri, A. (1999). Arabic Modifying Adjectives and DP Structures. Studia Linguistica 53, 104154.

Frank, S. and Progovac, L. (1994). On the Placement of Serbo-Croatian Clitics. Indian Linguistic Studies 7, 69-78.

Gavarro, A. and Sola, J. (2004). Wh-Subextraction in Child Language. Paper Presented at the Second Lisbon Meeting on Language Acquisition, Universidade de Lisboa.

Gavruseva, E. (2000). On the Syntax of Possessor Extraction. Lingua 110. 743-772.

Gavruseva, E. and Thornton, R. (2001). Getting it right: Acquisition of Whose-questions in Child English. Language Acquisition 9:3.229-267.

Giorgi, A. and Longobardi, G. (1991). The Syntax of Noun Phrases: Configurations, Parameters and Empty Categories. Cambridge University Press, New York.

Hoekstra, T, C. Koster and T. Roeper. (1992). "Left Branch Violations in Acquisition". A Paper Presented at the Boston University Conference on Language Development. Boston.

Hurford, J. (1975). The Linguistic Theory of Numerals. Cambridge: Cambridge University Press.

Hurford, J. (1987). Language and Number. Oxford: Basil Blackwell.

Hurford, J. (2001). Numeral Systems. In N. J. Smelser and P. B. Baltes (eds.), International Encyclopedia of the Social and Behavioral Sciences. Pergamon. Amsterdam. 10756-10716. 
Hurford, J. (2003) The Interaction between Numerals and Nouns. In Frans Plank (ed.) Noun Phrase Structure in the Language of Europe, 561-620. Empirical Approaches to Languages Typology/ Eurotyp, Mouton de Gruyter.

Ionin, T. and O. Matushansky. (2006). The Composition of Complex Cardinals. Journal of Semantics 23: 315-360.

Kayne, R. (2002). One Some Prepositions that Look DP internal: English of the French de. Catalan Working Papers in Linguistics 2. 71-115.

Kim, Sun-Woong. (2011). A Note on NP/DP Parameter: Left Branch Extraction in Korean. Linguistic Research 28 (2), 257-269.

Kremers, J. (2003). Arabic Noun Phrase. Netherlands: LOT.

Mohammad, M. (1988). On the Parallelism Between IP and DP. In H. Borer (ed.) Proceedings of WCCFL 7: 241-254.

Mohammad, M. (1999). Checking and Licensing inside DP in Palestinian Arabic. In Benmamoun Elabbas (ed.). Perspectives on Arabic Linguistics 12: Papers from the Twelfth Annual Symposium on Arabic Linguistics. Amsterdam: John Benjamins. 27-44.

Nelson, D. and Toivonen, I. (2000). Counting and the Grammar: Case and Numerals in Inari Sami. In D. Nelson and P. Foulkes (Eds.), Leeds Working Papers in Linguistics, 8: 179-192.

Ntelitheos, D. (2002). Possessor Extraction in Greek and the Left Periphery of the DP. Unpublished Master. UCLA. http://faculty.uaeu.ac.ae/dimitrios_n/Poss.pdf.

Obenauer, H. (1984). On the Identification of Empty Categories. The linguistic Review 4-2. 153-202.

Ouwayda, S. (2010). Construct State Nominals as Semantic Predicates. In Arabic Language and Linguistics. (Ed.) by Reem Bassiouney and E. Graham Katz, 79-98. Georgetown University Press.

Ouwayda, S. (2012). Cardinals Without Plurality. In Proceedings of Sinn and Bedeutung 16. Vol. 2. Page 489. By Ana Agullar Gnevara, Anna Chernilovskaye, and Rick Nouwen 2012.

Ouwayda, S. (2013). Composing Additive Complex Numerals in the DP. In Proceedings of the Fortieth Western Conference On Linguistics (WECOL) V. 21 page 144-154, (Ed.) by Claire Renaud, Carla Ghanem, Veroniaca Gonzalez Lopez and Kathryn Pruitt, California State University, Fresno.

Ouwayda, S. (2014). Where Number Lies: Plural Marking Numerals, and the Collective Distributive Distinction. PhD Dissertation. University of Southern California.

Ritter, E. (1987). NSO Orders in Modern Hebrew. In J. McDonough and B. Plunkett (eds.), Proceedings of the North East Linguistic Society 17, 521-537.

Ritter, E. (1988). A Head Movement Approach to Construct State Noun Phrases. Linguistics 26, 909929. 
Ritter, E. (1991). Two Functional Categories in Noun Phrases. In Susan Rothstein (ed.), Perspectives on Phrase Structure: Heads and Licensing, 37-62, California: Academic Press.

Ross, J. (1967). Constraints on Variables in Syntax. Doctoral Dissertation, MIT.

Shlonsky, U. (1988). Government and Binding in Hebrew Nominals. Linguistics 26. 951-976.

Shlonsky, U. (1991). Quantifiers and Functional Heads: a Study of Quantifier Float in Hebrew. Lingua 84, 159-180.

Shlonsky, U (2002). Constituent Questions in Palestinian Arabic. In Ouhalla Jamal and Ur Shlonsky (eds.) Themes in Arabic and Hebrew Syntax. Kluwer Academic Publishers, Dordrrecht, 137160.

Shlonsky, U. (2004). The Form of Semitic Noun Phrases. Lingua 114, 1465-1526.

Shlonsky, U. (2012). On Some Properties of Nominals in Hebrew and Arabic: The "Construct State" and the Mechanisms of AGREE and MOVE. Rivista di Linguistica 24.2, 267-286.

Sichel, I. (2002). Phrasal Movement in Hebrew Adjectives and Possessives. In Slexiadou Artemis, Elena Anagnostopoulou, Sjef Barbiers, and Hans Martin Gartner (eds.). Dimensions of Movement. Amsterdam: John Benjamins. 297-339.

Sichel, I. (2003). Phrasal Movement in Hebrew DPs. In Lecarme Jacqueline (ed.) Research in Afroasiatic Grammar Two. Amsterdam: John Benjamines. 297-339.

Siloni, T. (1991a). Noun Raising and the Structure of Noun Phrases. In Bobaljik, J. and T. Bures (eds.) MIT Working Papers in Linguistics 14: 255-270.

Siloni, T. (1991b). Construct State at the PF Interface. Linguistic Variation Yearbook 1, 229-266.

Siloni, T. (1994). Noun Phrases and Nominalizations: the Syntax of DPs. Dordrecht: Kluwer.

Siloni, T. (1997). Event Nominals and the Construct State. In L. Haegeman (Ed.), New Comparative Syntax p. 165-188, New York, Longman.

Siloni, T. (2002). Adjectival Constructs and Inalienable Constructions. In Jamal Ouhala and Ur Shlonsky (eds.), Themes in Arabic and Hebrew Syntax, 161-188. Dordrecht: Kluwer.

Thorne, D. (1993). A Comprehensive Welsh Grammar. Oxford Blackwell.

Uriagereka, J. (1988). On Government. PhD Dissertation, University of Connecticut.

van Kampen, J. (1994). The Learnability of the Left Branch Condition. Linguistics in the Netherlands 1994, ed. By R. Bok-Bennema and C. Cremers, 83-94. Amsterdam: John Benjamins.

van Kampen, J. (1997). First Steps in Wh-Movement. PhD dissertation. Utrecht University.

van Kampen, J. (2000). Left Branch Extraction as Operator Movement: Evidence from Child Dutch. The Acquisition of Scrambling and Cliticization, ed, by Susan Powers and Cornelia Hamann. Dordrecht: Kluwer. 
Vries, M. (2006). The Syntax of Appositive Relativization: on Specifying Coordination, False Free Relatives and Promotion. Linguistic Inquiry 37: 2, 229-270.

Zabbal, Y. (2005). They Syntax of Numeral Expressions. MS, University of Massachusetts, Amherst.

Zweig. E. (2005). Nouns and Adjectives in Numerals NPs. In Leah Bateman and Cherlon Ussery (Eds.), Proceedings of NELS 35, 663-675. Amherst, Massachusetts: GLSA Publications.

\section{Contact details of author}

Dr Khalaf M. J. AlShammiry

Associate Professor of Linguistics

King Saud University, College of Languages and Translation (COLT),

Riyadh, Kingdom of Saudi Arabia

and

Vice President for Development, Quality and Community Service

Northern Border University,

Arar, P.O. Box 1321, Kingdom of Saudi Arabia

Email: Dr.Khalafmj@yahoo.com

\section{Biodata}

Dr Khalaf M. J. AlShammiry earned his doctorate degree $(\mathrm{PhD})$ from University of Kansas, Lawrence, Kansas, USA in 2007. He was an Associate Professor of Linguistics at King Saud University (KSU) from 2007 until 2010. Currently, he is working as the Vice President for Academic Affairs, and the Vice President Development, Quality and Community Service at Northern Border University (NBU). 